\title{
Mental health law in Greece
}

\author{
A. Douzenis, ${ }^{1}$ C. Tsopelas $^{2}$ and L. Lykouras ${ }^{3}$
}

${ }^{1}$ Assistant Professor in Forensic Psychiatry, Second Psychiatry Department, Forensic Psychiatric Unit, Athens University Medical School, Greece, email thandouz@ med.uoa.gr

${ }^{2}$ Consultant Psychiatrist, Psychiatric Hospital of Attika Greece

3Professor in Psychiatry, Second Psychiatry Department, Athens University Medical School, Greece
Like all European countries, Greece has developed its national legislation based on the principles of equality and the right of representation, but there is no separate, specific mental health law in Greece. This paper describes the law for involuntary psychiatric admission. The law concerning criminal and civil responsibility and the law relating to individuals with addictions committing drug-related crimes are also outlined.

\section{Involuntary admission}

In Greece, involuntary admissions are regulated by Law 2071/92, which in 1992 replaced the previous legislation governing involuntary psychiatric hospitalisation. This change was necessary in order to bring Greek legislation into line with the legal prerequisites for joining the European Union. When the law was introduced it was recognised as an important, albeit belated, step towards acknowledging and securing the rights of people with mental illness. The law recognised, for instance, for the first time in Greece their right to appeal against involuntary hospitalisation.

In particular, Law 2071 describes two procedures to be followed for involuntary admissions: 'normal' and 'emergency'. The 'normal' procedure requires two separate psychiatric assessments by 'approved' psychiatrists to be completed before admission. In fact, the 'normal' procedure is almost never used (Douzenis et al, 2012).

\section{The emergency procedure}

The 'emergency' procedure by-passes the initial psychiatric assessments; instead, the relatives requesting the admission are put in direct contact with a public prosecutor (there are a number of these officials, one of whom will be on duty on any particular day). The individual for whom a relative has requested a psychiatric assessment for involuntary admission is escorted by the police to the psychiatric emergency department (for this purpose, one such department is nominated to be on call on any particular day). Alternatively, in the absence of the 'nearest relative', the procedure for involuntary admission is instigated ex officio, where the public prosecutor makes the application and orders the police to take the individual for assessment. The public prosecutor gives this order in writing after being alerted by the police or a member of the public (e.g. a neighbour). Only in cases of grave emergency can the public prosecutor order the police verbally.

Once people due to be assessed arrive in the psychiatric unit on call, they are examined by two qualified psychiatrists. The mental health assessment needs to establish: that they suffer from a mental illness and are unable to look after themselves; and that they refuse treatment because of lack of insight. Furthermore, the examining psychiatrists need to be convinced that if the mental disorder remains untreated, then the patient's life or the lives of others might be at risk. If the psychiatrists establish that these prerequisites for involuntary admission are present, then, after the appropriate forms are completed (which are returned to the public prosecutor), the individual is admitted involuntarily. The public prosecutor then brings the case before a court within 10 days (Douzenis et al, 2013). The individual examined and deemed to be suffering from a psychiatric disorder can appear in that court and argue against involuntary admission, with legal representation.

The maximum time for involuntary admission is 6 months. The public prosecutor requests medical reports after 3 months and again at the end of the 6 months (in the rare instances when a patient is not discharged earlier).

After patients are involuntarily admitted they can be discharged whenever the responsible medical officer decides that the criteria for involuntary admission are no longer met. Involuntarily in-patient treatment lasts on average 4-6 weeks (Douzenis \& Lykouras, 2008). No one can be treated involuntarily in the community. Involuntary 'admission' in fact means involuntary treatment during the period of hospitalisation.

\section{Mental capacity Penal code}

The law accepts that there are instances when a mental disorder may impair the individual's ability to differentiate between right and wrong and interfere with free will. Offenders with a mental disorder should primarily be considered as ill and therefore exempt from punishment.

Article 34 of the Greek Penal Code states:

A criminal act is not attributable to the perpetrator if because of a disturbance of his mental functions, or a disturbance of conscience, he did not possess the ability to acknowledge the wrongfulness of this act or to act according to this knowledge.

If the court accepts that this is the case, the perpetrator is considered not guilty of the crime, that is, 'not guilty by reason of insanity', and is admitted to a psychiatric hospital for 'the protection of others and treatment' (Article 69).

If the ability 'to acknowledge the wrongfulness of the act' is not totally absent but only reduced, there is diminished responsibility for the criminal act and thus a reduced punishment (Article 36). 


\section{Civil Code}

According to Article 128 of the Greek Civil Code, all adults (i.e. those aged over 18 years) are considered legally responsible (e.g. are able to sign legal documents). A person arguing that someone is incapacitous has to prove the incapacity and not vice versa. Articles 129 and 130 clarify the concept of diminished capacity. Individuals may have the right to decide some of their own affairs under certain circumstances. The ability of someone to make a will is closely connected with the above (Androulakis, 1986).

\section{Legislation on substance misuse and offending behaviour}

The current legislation on substance misuse (Law 3459/2006, called the Code of Laws on Narcotics) introduced the concept of 'decriminalisation' for individuals dependent on illegal substances. This legislative reform aims to encourage treatment initiation and reduce prison sentences for individuals with addictions (mainly heroin addiction) who commit petty offences (Kotsalis et al, 2007).

If a court accepts that defendants are addicted, then they can receive a reduced sentence, as indicated above for persons with a mental illness. Defendants making such a claim as part of their defence have to be examined by a psychiatrist and receive a psychiatric report confirming the presence or absence of addiction (according to the DSM-IV-TR criteria). This can be difficult to achieve since the psychiatrist is not called immediately after the arrest.

\section{Discussion}

Although in theory the law safeguards human rights, in practice a lack of resources makes its application problematic. For instance, the ombudsman (a citizens' advocate for civil rights) in Greece, in a special report published in 2007, indicated that mental health professionals are not acting according to the legal prerequisites (Department of Health and Social Welfare, 2007). The medical reports often contain no clear record of an assessment of a patient's ability to decide on healthcare and the stock phrase the prerequisites for law 2071 are met' is often used. Additionally, it was not certain that patients were being properly informed about their right of legal appeal. More disturbingly, though, the ombudsman discovered that no court decision was recorded for $84 \%$ of the cases of involuntary admission and that for the majority of cases the rule that there should be a maximum 10-day wait for a court decision had not been met. These findings indicate that the legal system is treating involuntary admissions without due process. New ways of approaching the right of appeal, including the 'Greek equivalent' of mental health review tribunals, have been suggested by the Greek Forensic Psychiatry Association. It is more than 20 years since the introduction of Law 2071, and it now needs to be updated and redrafted.

\section{References}

Androulakis, M. (1986) Penal Code. General Part (vol. 3) [in Greek]. Sakkoulas Publications.

Department of Health and Social Welfare (2007) Special Report: Own-Initiative Investigation by the Ombudsman into the Involuntary Hospitalisation of Mentally III Patients. Department of Health and Welfare. Summary available at http://www.synigoros. $\mathrm{gr} /$ ? i=health-and-social-welfare.en.recentinterventions. 35018 (accessed December 2013).

Douzenis, A. \& Lykouras, L. (eds) (2008) Forensic Psychiatry [in Greek]. Paschalides Publications.

Douzenis, A., Michopoulos, I., Economou, M., et al (2012) Involuntary admission in Greece: a prospective national study of police involvement and client characteristics affecting emergency assessment. International Journal of Social Psychiatry, 58, 172-177.

Douzenis, A., Michopoulos, I., Gournellis, R., et al (2013) Differences between elderly voluntary and involuntary admitted patients in Greece. International Psychogeriatrics, 25, 25-33.

Kotsalis, L., Margaritis, M. \& Farsedakis, I. (2007) Legislation on Narcotics. Explanatory Comments of Law 3459/2006 on Narcotics [in Greek]. Sakkoulas Publications.
MENTAL HEALTHLAW PROFILE

\title{
Mental health law in Turkey: legislation pending
}

\author{
Esra Caglar ${ }^{1}$ MD MRCPsych and Muzaffer Kaser ${ }^{2}$ MD MPhil
}

${ }^{1}$ Consultant Child and Adolescent Psychiatrist, London, UK, email esra@caglar.com

${ }^{2}$ Psychiatrist, PhD Candidate at the Department of Psychiatry, University of Cambridge, Visiting Lecturer at Bahcesehir University, Istanbul, Turkey
In Turkey, mental health professionals, together with patients and carers, have been involved in the drafting of the Mental Health Bill which is presently under consideration by Parliament. While the Mental Health Law is pending, various pieces of legislation are being used for different types of involuntary admission. The prospective Mental Health Law is of paramount importance for doctors, patients and families.
The Mental Health Law in Turkey is still at the proposal stage and has not yet been enacted (Psychiatric Association of Turkey, 2007). This has significant repercussions. Various groups, including clinicians, patients and carers, are affected and take on major responsibilities to compensate for the lack of specific mental health legislation. Currently, clinical practice is heavily influenced by cultural factors, such as carers' attitudes towards people who are mentally ill and the family's 